\title{
TANTANGAN BADAN PENYELENGGARA JAMINAN SOSIAL KESEHATAN (BPJS) DALAM RANGKA MEWUJUDKAN KESEJAHTERAAN RAKYAT
}

\begin{abstract}
Astrid Teresa
ABSTRAK

Upaya Negara Indonesia untuk memberikan jaminan kesehatan yang layak dituangkan dalam Undang-Undang Nomor 24 Tahun 2011yaitu membentuk BPJS guna tercapainya Universal Healt coverage (UHC) di tahun 2019. BPJS Kesehatan sebagai pelaksana kebijakan sudah berupaya maksimal untuk memberikan sosialisasi dan meningkatkan kesadaran masyarakat akan pentingnya untuk jaminan kesehatan, namun memang butuh proses dan waktu untuk mewujudkan keseluruhan warga negara terjamin dalam jaminan kesehatan nasional. Namun tidak dapat dipungkiri masih banyak kendala yang dihadapi baik dari internal maupun eksternal sehingga Pelayanan JKN oleh BPJS masih belum diterima seluruh penduduk Indonesia.
\end{abstract}

\section{PENDAHULUAN}

Pemerintah telah mencanangkan Visi Indonesia menjadi negara maju pada tahun 2025. Untuk mencapai visi tersebut diperlukan Sumber Daya Manusia (SDM) yang berkualitas. Namun hal tersebut masih menjadi tantangan bagi negara kita karena fasilitas pendidikan dan kesehatan yang berkualitas sebagai modal terwujudnya SDM yang mumpuni masih belum tersebar merata di seluruh wilayah Indonesia. Demi terwujudnya layanan kesehatan yang mudah diakses, Pemerintah menerbitkan Undang-Undang Nomor 40 Tahun 2004 tentang Sistem Jaminan Sosial Nasional (UU SJSN) dan Undang-Undang Nomor 24 Tahun 2011 tentang Badan Penyelenggara Jaminan Sosial (UU BPJS).

Dengan diterbitkan kedua undang-undang yang dimaksud, Pemerintah harus memberikan lima jaminan dasar bagi seluruh masyarakat Indonesia yaitu jaminan kesehatan, kecelakaan kerja, kematian, pensiun, dan tunjangan hari tua yang mana jaminan tersebut harus dibayarkan oleh perseorangan, pemberi kerja, dan/atau Pemerintah. Dengan demikian pelayanan kesehatan akan menerapkan kebijakan Universal Health Coverage (UHC) yang didorong oleh WHO, yakni jaminan kesehatan untuk semua penduduk. Pada tanggal 1 Januari 2014 didirikan Badan Penyelenggara Jaminan Sosial (BPJS) Kesehatan yang selaras dengan tujuan Organisasi Kesehatan Dunia. BPJS bertugas untuk untuk memenuhi kebutuhan pelayanan kesehatan masyarakat dan menentukan cara yan efektif dalam menjaga mutu pelayanan kesehatan.

Badan Penyelenggara jaminan Sosial Kesehatan adalah badan hukum publik yang bertanggungjawab kepada Presiden dan berfungsi menyelenggarakan program jaminan kesehatan. Pada 1 Januari 2014 Pemerintah mengoprasikan BPJS Kesehatan atas perintah UU BPJS. Sejak BPJS Kesehatan beroprasi menyelenggarakan 
program-program pelayanan kesehatan perorangan, terjadi pengalihan program sebagai berikut:

a. Kementerian Kesehatan tidak lagi menyelenggarakan program jaminan kesehatan masyarakat (Jamkesmas);

b. Kementerian Pertanahan, Tentara Nasional Indonesia, dan Kepolisian Republik Indonesia tidak lagi menyelenggarakan program pelayanan kesehatan bagi pesertanya, kecuali untuk pelayanan kesehatan tertentu berkaitan dengan kegiatan operasionalnya, yang ditetapkan dengan Peraturan Presiden;

c. PT Jamsostek (Persero) tidak lagi menyelenggarakan program jaminan pemeliharaan kesehatan.

\section{VISI DAN MISI}

Dalam penyelenggaraannya BPJS Kesehatan memiliki Visi dan Misi untuk mencapai mutu pelayanan yang baik kepada seluruh penduduk Indonesia peserta jaminan kesehatan nasional ini.

a. Visi BPJS Kesehatan

Paling lambat 1 Januari 2019, seluruh penduduk Indonesia memiliki jaminan kesehatan nasional untuk memperoleh manfaat pemeliharaan kesehatan dan perlindungan dalam memenuhi kebutuhan dasar kesehatannya yang diselenggarakan oleh BPJS Kesehatan yang handal, unggul, dan terpercaya.

b. Misi BPJS Kesehatan

1. Membangun kemitraan strategis dengan berbagai lembaga dan mendorong partisipasi masyarakat dalam perluasan kepesertaan Jaminan Kesehatan Nasional (JKN);

2. Menjalankan dan memantapkan sistem jaminan pelayanan kesehatan yang efektif, efisien, dan bermutu kepada peserta melalui kemitraan yang optimal dengan fasilitas kesehatan;

3. Mengoptimalkan pengelolaan dana program jaminan sosial dan dana BPJS Kesehatan secara efektif, efisien, transparan, dan akuntabel untuk mendukung kesinambungan program;

4. Membangun BPJS Kesehatan yang efektif berlandaskan prinsip-prinsip tata kelola organisasi yang baik dan meningkatkan kompetensi pegawai untuk mencapai kinerja unggul;

5. Mengimplementasikan dan mengembangkan sistem perencanaan dan evaluasi, kajian, manajemen mutu dan manajemen resiko atas seluruh operasionalisasi BPJS Kesehatan;

6. Mengembangkan dan memantapkan teknologi informasi dan komunikasi untuk mendukung operasionalisasi BPJS Kesehatan.

\section{KEPESERTAAN}

Di dalam Undang-Undang Nomor 40 Tahun 2004 tentang Sistem Jaminan Sosial Nasional (SJSN) diamanatkan bahwa seluruh penduduk wajib menjadi peserta 
jaminan kesehatan termasuk WNA yang tinggal di Indonesia lebih dari 6 bulan wajib menjadi peserta dan harus membayar iuran jaminan kesehatan.

Bagi yang mempunyai upah atau gaji, besaran iuran berdasarkan persentase upah atau gaji dibayar oleh pekerja dan pemberi kerja. Bagi yang tidak mempunyai gaji atau upah besaran iurannya ditentukan dengan nilai nominal tertentu, sedangkan bagi masyarakat miskin dan tidak mampu membayar iuran maka iurannya dibayari pemerintah (Peraturan Presiden Republik Indonesia Nomor 12 Tahun 2013 Pasal 16).

Berdasarkan Peraturan Presiden Republik Indonesia Nomor 12 Tahun 2013 tentang Jaminan Kesehatan Bab II tentang peserta dan kepesertaan yang tercantum dalam Pasal 2 bahwa peserta Jaminan Kesehatan meliputi:

a. PBI (yang selanjutnya disebut Penerima Bantuan Iuran) jaminan kesehatan, adalah peserta Jaminan Kesehatan bagi fakir miskin dan orang tidak mampu sebagaimana diamanatkan Undang-undang SJSN yang iurannya dibayarkan oleh pemerintah sebagai peserta program Jaminan Kesehatan. Peserta PBI adalah fakir miskin yang ditetapkan oleh pemerintah dan diatur melalui Peraturan Pemerintah

b. Bukan PBI jaminan kesehatan merupakan Peserta yang tidak tergolong fakir miskin dan orang tidak mampu yang terdiri atas:

1. Pekerja Penerima Upah dan anggota keluarganya, meliputi:

a) Pegawai Negeri Sipil (PNS);

b) Anggota TNI;

c) Anggota Polri;

d) Pejabat Negara;

e) Pegawai Pemerintah Non Pegawai Negeri;

f) Pegawai Swasta;

g) Pekerja yang tidak termasuk huruf a sampai huruf f yang menerima upah.

2. Pekerja Bukan Penerima Upah dan anggota keluarganya, meliputi:

a) Pekerja di luar hubungan kerja atau pekerja mandiri; dan

b) Pekerja yang tidak termasuk huruf a yang bukan penerima upah.

3. Bukan Pekerja dan anggota keluarganya, meliputi:

a) Investor;

b) Pemberi Kerja;

c) Penerima Pensiun;

d) Veteran;

e) Perintis Kemerdekaan; dan

f) Bukan pekerja yang tidak termasuk huruf a sampai dengan huruf e yang mampu membayar iuran.

\section{PROSEDUR PENDAFTARAN PESERTA}

Setiap orang, termasuk orang asing yang bekerja paling singkat 6 (enam) bulan di Indonesia, wajib menjadi peserta program jaminan sosial, termasuk di dalamnya BPJS Kesehatan (Undang-Undang Nomor 24 Tahun 2011 tentang BPJS Pasal 14). 
Peserta jaminan kesehatan adalah setiap orang yang telah membayar iuran atau iurannya dibayar oleh pemerintah. Anggota keluarga peserta berhak menerima manfaat jaminan kesehatan. Setiap peserta dapat mengikutsertaan anggota keluarga yang lain yang menjadi tanggungannya dengan penambahan iuran (Undang-Undang Nomor 40 Tahun 2004 tentang Sistem Jaminan Sosial Nasional Pasal 20).

Berdasarkan Peraturan Presiden Republik Indonesia Nomor 12 Tahun 2013 tentang Jaminan Kesehatan Bab III tentang Pendaftaran Peserta dan Perubahan Data Kepesertaan yang tercantum dalam Pasal 10 bahwa Prosedur Pendaftaran Peserta, meliputi:

a. Pemerintah mendaftarkan PBI Jaminan Kesehatan sebagai Peserta kepada BPJS Kesehatan;

b. Pemberi kerja mendaftarkan pekerjanya atau pekerja dapat mendaftarkan diri sebagai peserta kepada BPJS Kesehatan;

c. Bukan pekerja dan peserta lainnya wajib mendaftarkan diri dan keluarganya sebagai peserta kepada BPJS Kesehatan.

\section{IURAN}

Iuran adalah sejumlah uang yang dibayar secara teratur oleh peserta, pemberi kerja, dan/atau pemerintah (Undang-Undang Nomor 40 Tahun 2004 tentang Sistem Jaminan Sosial Nasional Pasal 1). Besaran dan tata cara pembayaran iuran program jaminan kesehatan diatur dalam Peraturan Presiden Republik Indonesia Nomor 12 Tahun 2013 tentang Jaminan Kesehatan (Undang-Undang Nomor 24 Tahun 2011 tentang BPJS Pasal 19).

Berdasarkan Peraturan Presiden Republik Indonesia Nomor 12 Tahun 2013 tentang Jaminan Kesehatan Bab IV tentang Iuran yang tercantum dalam Pasal 17 bahwa Iuran Peserta Jaminan Kesehatan Nasional, meliputi:

a. Pemberi Kerja wajib membayar Iuran Jaminan Kesehatan seluruh Peserta yang menjadi tanggung jawabnya pada setiap bulan yang dibayarkan paling lambat tanggal 10 setiap bulan kepada BPJS Kesehatan. Apabila tanggal 10 jatuh pada hari libur, maka iuran dibayarkan pada hari kerja berikutnya. Keterlambatan pembayaran Iuran Jaminan Kesehatan dikenakan denda administrasi sebesar 2\% per bulan dari total iuran yang tertunggak dan dibayar oleh Pemberi Kerja;

b. Peserta Pekerja Bukan Penerima Upah dan Peserta bukan Pekerja wajib membayar Iuran Jaminan Kesehatan pada setiap bulan yang dibayarkan paling lambat tanggal 10 setiap bulan kepada BPJS Kesehatan. Pembayaran Iuran Jaminan Kesehatan dapat dilakukan di awal untuk lebih dari 1 bulan;

c. Pilihan iuran sesuai kelas perawatan adalah sebagai berikut:

1. Kelas 1: Rp. 80.000 per orang per bulan;

2. Kelas 2: Rp. 51.000 per orang per bulan;

3. Kelas 3: Rp. 30.000 per orang per bulan. 


\section{PRINSIP SISTEM JKN}

Jaminan Kesehatan Nasional (JKN) mengacu pada prinsip-prinsip Sistem Jaminan Sosial Nasional (SJSN) berikut:

\section{Prinsip Kegotongroyongan}

Dalam SJSN, prinsip gotong royong berarti peserta yang mampu membantu peserta yang kurang mampu, peserta yang sehat membantu yang sakit atau yang berisiko tinggi, dan peserta yang sehat membantu yang sakit. Hal ini terwujud karena kepesertaan SJSN bersifat wajib untuk seluruh penduduk, tanpa pandang bulu. Dengan demikian, melalui prinsip gotong royong jaminan sosial dapat menumbuhkan keadilan sosial bagi seluruh rakyat Indonesia.

2. Prinsip Nirlaba

Pengelolaan dana amanat oleh Badan Penyelenggara Jaminan Sosial (BPJS) adalah nirlaba bukan untuk mencari laba (for profit oriented). Sebaliknya, tujuan utama adalah untuk memenuhi sebesar-besarnya kepentingan peserta. Dana yang dikumpulkan dari masyarakat adalah dana amanat, sehingga hasil pengembangannya, akan di manfaatkan sebesar besarnya untuk kepentingan peserta.

3. Prinsip Keterbukaan, Kehati-hatian, Akuntabilitas, Efisiensi, dan Efektivitas.

Prinsip-prinsip manajemen ini mendasari seluruh kegiatan pengelolaan dana yang berasal dari iuran peserta dan hasil pengembangannya.

4. Prinsip Portabilitas

Prinsip portabilitas jaminan sosial dimaksudkan untuk memberikan jaminan yang berkelanjutan kepada peserta sekalipun mereka berpindah pekerjaan atau tempat tinggal dalam wilayah Negara Kesatuan Republik Indonesia.

5. Prinsip Kepesertaan Bersifat Wajib

Kepesertaan wajib dimaksudkan agar seluruh rakyat menjadi peserta sehingga dapat terlindungi. Meskipun kepesertaan bersifat wajib bagi seluruh rakyat, penerapannya tetap disesuaikan dengan kemampuan ekonomi rakyat dan pemerintah serta kelayakan penyelenggaraan program.

6. Prinsip Dana Amanat

Dana yang terkumpul dari iuran peserta merupakan dana titipan kepada badanbadan penyelenggara untuk dikelola sebaik-baiknya dalam rangka mengoptimalkan dana tersebut untuk kesejahteraan peserta.

7. Prinsip Hasil Pengelolaan Dana Jaminan Sosial

Dipergunakan seluruhnya untuk pengembangan program dan untuk sebesar-besar kepentingan peserta.

\section{MANFAAT}

Manfaat Jaminan Kesehatan Nasional (JKN) BPJS Kesehatan meliputi:

1. Pelayanan kesehatan tingkat pertama, yaitu pelayanan kesehatan non spesialistik mencakup:

a. Administrasi pelayanan

b. Pelayanan promotif dan preventif 
c. Pemeriksaan, pengobatan dan konsultasi medis

d. Tindakan medis non spesialistik, baik operatif maupun non operatif

e. Pelayanan obat dan bahan medis habis pakai

f. Transfusi darah sesuai kebutuhan medis

g. Pemeriksaan penunjang diagnosis laboratorium tingkat pertama

h. Rawat inap tingkat pertama sesuai indikasi

2. Pelayanan kesehatan rujukan tingkat lanjutan, yaitu pelayanan kesehatan mencakup:

a. Rawat jalan, meliputi:

1) Administrasi pelayanan

2) Pemeriksaan, pengobatan dan konsultasi spesialistik oleh dokter spesialis dan sub spesialis

3) Tindakan medis spesialistik sesuai dengan indikasi medis

4) Pelayanan obat dan bahan medis habis pakai

5) Pelayanan alat kesehatan implant

6) Pelayanan penunjang diagnosis lanjutan sesuai dengan indikasi medis

7) Rehabilitasi medis

8) Pelayanan darah

9) Pelayanan kedokteran forensik

10) Pelayanan jenazah di fasilitas kesehatan

b. Rawat Inap yang meliputi:

1) Perawatan inap non intensif

2) Perawatan inap di ruang intensif

3) Pelayanan kesehatan lain yang ditetapkan oleh Menteri.

Meskipun manfaat yang dijamin dalam JKN bersifat komprehensif, masih ada beberapa penangan medis yang tidak dijamin meliputi:

a) Tidak sesuai prosedur;

b) Pelayanan di luar Fasilitas Kesehatan yang bekerja sama dengan BPJS;

c) Pelayanan bertujuan kosmetik;

d) General checkup, pengobatan alternatif;

e) Pengobatan untuk mendapatkan keturunan, pengobatan impotensi;

f) Pelayanan kesehatan pada saat bencana; dan

g) Pasien Bunuh Diri /Penyakit yang timbul akibat kesengajaan untuk menyiksa diri sendiri/ Bunuh Diri/Narkoba.

\section{HAK DAN KEWAJIBAN PESERTA BPJS}

Dalam Pasal 1 Undang-Undang Kesehatan Nomor 23 Tahun 1992, kesehatan merupakan kondisi sejahtera dari badan, jiwa, dan sosial yang memungkin setiap orang produktif secara ekonomis. Oleh karena itu kesehatan merupakan dasar dari diakuinya derajat kemanusiaan. 
Secara internasional pentingnya kesehatan sebagai hak asasi manusia telah diakui dalam Pasal 25 Universal Declaration of Human Rights (UDHR) menyatakan bahwa:

1. Setiap orang berhak atas taraf kehidupan yang memadai untuk kesehatan dan kesejahteraan dirinya sendiri dan keluarganya, termasuk hak atas pangan, sandang, papan, dan pelayanan kesehatan, pelayanan sosial yang diperlukan, serta hak atas keamanan pada saat menganggur, sakit, cacat, ditinggalkan oleh pasangannya, lanjut usia, atau keadaan-keadaan lain yang mengakibatkan merosotnya taraf kehidupan yang terjadi diluar kekuasaannya.

2. Ibu dan anak berhak mendapatkan perhatian dan bantuan khusus. Semua anak, baik yang dilahirkan di dalam maupun di luar perkawinan, harus menikmati perlindungan sosial yang sama.

Peserta BPJS Kesehatan memiliki hak-hak yang perlu dilindungi dan dihormati sebagai konsumen jasa layanan kesehatan. Mengenai hak dan kewajiban peserta BPJS Kesehatan, hal ini dapat kita liat pada ketentuan Pasal 24 hingga Pasal 26 Peraturan Badan Penyelenggara Jaminan Sosial Kesehatan Nomor 1 Tahun 2014 tentang Jaminan Penyelenggara Kesehatan.

Adapun hak-hak peserta BPJS Kesehatan, diantaranya:

a. Mendapatkan identitas peserta;

b. Mendapatkan Nomor Virtual Account;

c. Memilih fasilitas kesehatan tingkat pertama yang bekerjasama dengan BPJS Kesehatan yang bekerja sama;

d. Memperoleh Jaminan Kesehatan;

e. Menyampaikan pengaduan kepada Fasilitas Kesehatan dan/atau BPJS Kesehatan.

f. Mendapatkan informasi pelayanan kesehatan;

g. Mengikuti program asuransi kesehatan tambahan.

Peraturan Badan Penyelenggara Jaminan Kesehatan Nomor 1 Tahun 2014 Tentang Penyelenggara Jaminan Kesehatan juga mengatur kewajiban-kewajiban bagi peserta BPJS Kesehatan, diantaranya:

a. Membayar iuran;

b. Melaporkan perubahaan data kepersertaan;

c. Melaporkan perubahan status kepersertaan;

d. Melaporkan kerusakan dan/atau kehilangan kartu identitas peserta Jaminan Kesehatan.

\section{SISTEM RUJUKAN}

Sistem rujukan pelayanan kesehatan adalah penyelenggaraan pelayanan kesehatan yang mengatur pelimpahan tugas dan tanggung jawab pelayanan kesehatan secara timbal balik, baik vertikal maupun horizontal yang wajib dilaksanakan oleh peserta jaminan kesehatan atau asuransi kesehatan sosial, dan seluruh fasilitas kesehatan. Ketentuan umum pada sistem rujukan BPJS Kesehatan ini adalah sebagai berikut (Panduan Praktis Sistem Rujukan Berjenjang BPJS Kesehatan, 2014): 
a. Berdasarkan Peraturan BPJS Kesehatan Nomor 1 Tahun 2014 pelayanan kesehatan perorangan terdiri dari 3 tingkatan yaitu:

1. Pelayanan kesehatan tingkat pertama (Puskesmas, Praktek Dokter Umum, Praktek Dokter Gigi, Faskes Tingkat Pertama Milik TNI/Polri, dan Rumah Sakit Tipe D);

2. Pelayanan kesehatan tingkat kedua (Rumah Sakit Umum, Rumah Sakit Tipe B, Rumah Sakit Tipe C, dan Rumah Sakit Spesialis); dan

3. Pelayanan kesehatan tingkat ketiga (Rumah Sakit Sub-Spesialistik).

b. Pelayanan kesehatan tingkat pertama merupakan pelayanan kesehatan dasar yang diberikan oleh fasilitas kesehatan tingkat pertama.

c. Pelayanan kesehatan tingkat kedua merupakan pelayanan kesehatan spesialistik yang dilakukan oleh dokter spesialis atau dokter gigi spesialis yang menggunakan pengetahuan dan teknologi kesehatan spesialistik.

d. Pelayanan kesehatan tingkat ketiga merupakan pelayanan kesehatan sub spesialistik yang dilakukan oleh dokter sub-spesialis atau dokter gigi sub spesialis yang menggunakan pengetahuan dan teknologi kesehatan subspesialistik.

e. Dalam menjalankan pelayanan kesehatan, fasilitas kesehatan tingkat pertama dan tingkat lanjutan wajib melakukan sistem rujukan dengan mengacu pada peraturan perundang-undangan yang berlaku.

f. Peserta yang ingin mendapatkan pelayanan yang tidak sesuai dengan sistem rujukan dapat dimasukkan dalam kategori pelayanan yang tidak sesuai dengan prosedur sehingga tidak dapat dibayarkan oleh BPJS Kesehatan.

g. Fasilitas Kesehatan yang tidak menerapkan sistem rujukan maka BPJS Kesehatan akan melakukan recredentialing terhadap kinerja fasilitas kesehatan tersebut dan dapat berdampak pada kelanjutan kerjasama.

h. Pelayanan rujukan dapat dilakukan secara horizontal maupun vertikal.

i. Rujukan horizontal adalah rujukan yang dilakukan antar pelayanan kesehatan dalam satu tingkatan apabila perujuk tidak dapat memberikan pelayanan kesehatan sesuai dengan kebutuhan pasien karena keterbatasan fasilitas, peralatan dan/atau ketenagaan yang sifatnya sementara atau menetap.

j. Rujukan vertikal adalah rujukan yang dilakukan antar pelayanan kesehatan yang berbeda tingkatan, dapat dilakukan dari tingkat pelayanan yang lebih rendah ke tingkat pelayanan yang lebih tinggi atau sebaliknya.

k. Rujukan vertikal dari tingkatan pelayanan yang lebih rendah ke tingkatan pelayanan yang lebih tinggi dilakukan apabila:

1) Pasien membutuhkan pelayanan kesehatan spesialistik atau subspesialistik;

2) Perujuk tidak dapat memberikan pelayanan kesehatan sesuai dengan kebutuhan pasien karena keterbatasan fasilitas, peralatan dan/atau ketenagaan.

1. Rujukan vertikal dari tingkatan pelayanan yang lebih tinggi ke tingkatan pelayanan yang lebih rendah dilakukan apabila:

1. Permasalahan kesehatan pasien dapat ditangani oleh tingkatan pelayanan kesehatan yang lebih rendah sesuai dengan kompetensi dan kewenangannya; 
2. Kompetensi dan kewenangan pelayanan tingkat pertama atau kedua lebih baik dalam menangani pasien tersebut;

3. Pasien membutuhkan pelayanan lanjutan yang dapat ditangani oleh tingkatan pelayanan kesehatan yang lebih rendah dan untuk alasan kemudahan, efisiensi dan pelayanan jangka panjang; dan/atau

4. Perujuk tidak dapat memberikan pelayanan kesehatan sesuai dengan kebutuhan pasien karena keterbatasan sarana, prasarana, peralatan dan/atau ketenagaan.

m. Tata cara pelaksanaan sistem rujukan berjenjang:

1. Sistem rujukan pelayanan kesehatan dilaksanakan secara berjenjang sesuai kebutuhan medis, yaitu:

a) Dimulai dari pelayanan kesehatan tingkat pertama oleh fasilitas kesehatan tingkat pertama;

b) Jika diperlukan pelayanan lanjutan oleh spesialis, maka pasien dapat dirujuk ke fasilitas kesehatan tingkat kedua;

c) Pelayanan kesehatan tingkat kedua di faskes sekunder hanya dapat diberikan atas rujukan dari faskes primer;

d) Pelayanan kesehatan tingkat ketiga di faskes tersier hanya dapat diberikan atas rujukan dari faskes sekunder dan faskes primer.

2. Pelayanan kesehatan di faskes primer yang dapat dirujuk langsung ke faskes tersier hanya untuk kasus yang sudah ditegakkan diagnosis dan rencana terapinya, merupakan pelayanan berulang dan hanya tersedia di faskes tersier.

3. Ketentuan pelayanan rujukan berjenjang dapat dikecualikan dalam kondisi:

a) Terjadi keadaan gawat darurat;

b) Bencana;

c) Kekhususan permasalahan kesehatan pasien;

d) Pertimbangan geografis; dan

e) Pertimbangan ketersediaan fasilitas.

4. Pelayanan oleh bidan dan perawat:

a) Dalam keadaan tertentu, bidan atau perawat dapat memberikan pelayanan kesehatan tingkat pertama sesuai ketentuan peraturan perundangundangan;

b) Bidan dan perawat hanya dapat melakukan rujukan ke dokter dan/atau dokter gigi pemberi pelayanan kesehatan tingkat pertama kecuali dalam kondisi gawat darurat dan kekhususan permasalahan kesehatan pasien, yaitu kondisi di luar kompetensi dokter dan/atau dokter gigi pemberi pelayanan kesehatan tingkat pertama.

5. Rujukan Parsial

a) Rujukan parsial adalah pengiriman pasien atau spesimen ke pemberi pelayanan kesehatan lain dalam rangka menegakkan diagnosis atau pemberian terapi, yang merupakan satu rangkaian perawatan pasien di faskes tersebut; 
Hampir semua penyakit dapat ditanggung oleh BPJS Kesehatan dan untuk berobat dengan BPJS Kesehatan peserta harus mengikuti prosedur rujukan berjenjang, artinya jika tidak bisa ditangani di puskesmas, klinik, dokter keluarga, baru bisa dirujuk ke rumah sakit.

\section{HAMBATAN}

Dalam menjalankan program Jaminan Kesehatan Nasional ini pemerintah menemui berbagai halangan, diantaranya sebagai berikut:

1. Jumlah faslitas pelayanan kesehatan yang kurang mencukupi dan persebarannya kurang merata khususnya bagi Daerah Terpencil Perbatasan dan Kepulauan (DTPK) dengan tingkat utilisasi yang rendah akibat kondisi geografis dan tidak memadainya fasilitas kesehatan pada daerah tersebut.

2. Jumlah tenaga kesehatan yang ada masih kurang dari jumlah yang dibutuhkan.

3. Untuk pekerja sektor informal nantinya akan mengalami kesulitan dalam penarikan iurannya setiap bulan karena pada sektor tersebut belum ada badan atau lembaga yang menaungi sehingga akan menyulitkan dalam penarikan iuran di sektor tersebut.

4. Permasalahan akan timbul pada penerima PBI karena data banyak yang tidak sesuai antara pemerintah pusat dan daerah sehingga data penduduk tidak mampu tidak sesuai dengan kondisi di lapangan.

Dengan banyaknya jumlah peserta BPJS Kesehatan secara nasional dan sebagai suatu sistem yang besar dan baru berlangsung dalam tempo yang relatif singkat, Dewan Jaminan Sosial Nasional (DJSN) melakukan monitoring dan evaluasi terhadap pelayanan BPJS Kesehatan, dimana terdapat permasalahan dalam pengaplikasiannya, banyak masyarakat yang belum tahu teknis mendapatkan pelayanan sesuai dengan aturan BPJS Kesehatan, sehingga banyak peserta BPJS Kesehatan yang mengeluhkan dengan sistem pelayanan rujukan berjenjang yang diterapkan BPJS Kesehatan. Mutu pelayanan kesehatan sangat dipengaruhi oleh proses pemberian pelayanan. Setiap pasien memiliki perspektif berbeda mengenai mutu pelayanan kesehatan, hal tersebut dipengaruhi oleh karakteristik pasien yang terdiri dari jenis kelamin, umur, pendidikan, dan pekerjaan. Dengan adanya BPJS Kesehatan, mutu pelayanan yang diberikan pada pasien sudah ditentukan. Sebagian besar hal tersebut mempengaruhi kepuasan pasien peserta BPJS Kesehatan.

\section{HAMBATAN PELAKSANAAN JAMINAN KESEHATAN NASIONAL}

\section{Hambatan Eksternal}

1. Kurangnya kesadaran dari masyarakat Menumbuhkan kesadaran dalam diri masyarakat bukanlah hal yang mudah. Masih banyak masyarakat yang tidak mengerti pentingnya jaminan sosial dan prinsip subsidi silang yang dijalankan oleh BPJS. Masih ditemukan masyarakat dengan ekonomi menengah ke atas yang menggunakan BPJS golongan III dengan biaya 
premi terendah, dan beberapa masyarakat masih menganggap premi yang ditetapkan mahal.

2. Kesadaran bagi peserta mandiri untuk membayar iuran

Banyak pendaftar BPJS membayarkan iuran hanya disaat kondisi sakit. Setelah kondisi sakit teratasi iuran tidak lagi dibayarkan.

3. Peserta JKN belum paham sistem rujukan berjenjang dan prosedur pelayanan JKN Kurangnya sosialisasi mengenai sistem rujukan berjenjang membuat banyak masyarakat kebingungan dimana dapat mendapatkan pengobatan. Namun ditemukan juga masyarakat yang acuh ketika petugas menjelaskan mengenai system rujukan berjenjang ini.

\section{Hambatan internal}

1. Regulasi yang masih terus mengalami perubahan

Pemerintah selalu berupaya memberikan pilihan kebijakan yang terbaik bagi masyarakatnya, dengan peraturan perundang-undangan yang berlaku dan mengikat inilah kebijakan dapat ditegakkan dengan baik. Peraturan yang ada diupayakan untuk dibuat semaksimal mungkin. Dalam pelaksanaannya, pemerintah merasa masih banyak hal hal yang perlu diperbaiki dalam peraturannya, seperti misal mengenai perubahan kapitasi.

2. Pusat layanan kesehatan yang tidak merata

Ketidakmerataan pusat layanan kesehatan yang ada di Indonesia menyebabkan masyarakat harus menempuh jarak yang jauh untuk mendapatkan jasa layanan kesehatan yang layak. Sementara untuk menempuh jarak yang jauh tersebut diperlukan biaya yang tidak sedikit. Hal ini menjadikan masyarakat enggan untuk melakukan pengobatan meskipun sudah terdaftar sebagai peserta BPJS.

\section{KESIMPULAN}

Setiap orang berhak atas hidup sehat dan berhak mendapatkan pelayanan kesehatan yang sebaik-baiknya dan Pemerintah bertanggungjawab untuk untuk mewujudkannya hingga tercapainya derajat kesehatan yang setinggi-tingginya. Salah satu instrumen atau sarana penyelenggaraan pelayanan kesehatan adalah pembiayaan kesehatan. Melalui program jaminan kesehatan maka pembiayaan kesehatan dilembagakan, Pemerintah tidak mungkin menanggung beban, tugas dan tanggung jawab sendiri dalam rangka terwujudnya derajat kesehatan yang setinggi-tingginya tersebut, oleh karena itu Pemerintah mengatur partisipasi masyarakat, termasuk perusahaan. Regulasi dalam penyelenggaraan jaminan sosial kesehatan, sangat menentukan sukses tidaknya sistem jaminan sosial kesehatan untuk memperkokoh ketahanan nasional, dengan memberikan perlindungan kesehatan dan menjamin seluruh rakyat agar dapat memenuhi kebutuhan kesehatan sebagai salah satu kebutuhan dasar masyarakat. 
DAFTAR PUSTAKA

Anggriani SW. Kualitas Pelayanan Bagi Peserta BPJS Kesehatan dan Non BPJS Kesehatan. JISIP: Jurnal Ilmu Sosial dan Ilmu Politik;5(2):2016

Basuki EW, Sulistyowati, Herawati NR. Implementasi Kebijakan Jaminan Kesehatan Nasional oleh BPJS Kesehatan di Kota Semarang. Semarang: Diponegoro Journal Of Social And Political Of Science; 2016.

BPJS Kesehatan, 2014, Panduan Praktis Sistem Rujukan Berjenjang BPJS Kesehatan, BPJS Kesehatan.

BPJS Kesehatan, 2014, Peraturan BPJS Kesehatan Nomor 1 Tahun 2014, BPJS Kesehatan.

Undang-Undang Republik Indonesia Nomor 24, 2011, Badan Penyelanggara Jaminan Sosial, Republik Indonesia. 